\title{
Sentiment, Subjectivity, and Social Analysis Go To Work: An Industry View - Invited Talk
}

\author{
Seth Grimes \\ Alta Plana Corporation \\ grimesealtaplana.com
}

Affective computing has a commercial side. Numerous products and projects provide sentiment, emotion, and intent extraction capabilities, applied in consumer and financial markets, for healthcare and customer care, and for media, policy, and politics. Academic and industry researchers are naturally interested how sentiment and social technologies are being applied and in commercial market opportunities and trends, in what's being funded, what's falling flat, and what's on business's roadmap. Analyst Seth Grimes will provide an industry overview, surveying companies and applications in the sentiment and social analytics spaces as well as work at the tech giants. He will discuss commercialization strategy and the affective market outlook.

Dr. Seth Grimes is the leading industry analyst covering NLP, text analytics, sentiment analysis, and analysis on the confluence of structured and unstructured data sources. Seth founded Washington DC based Alta Plana Corporation, an information technology strategy consultancy, in 1997. He consults on product design, commercialization strategy, and the competitive market to established technology and solutions companies and startups. Seth created and organizes the industry-focused Sentiment Analysis Symposium and Language TechnologyAccelerate conferences and was founding chair of the Text Analytics Summit (2005-13). He writes frequently for trade-press outlets including VentureBeat, KDNuggets, and InformationWeek and for his own Breakthrough Analysis blog. He is on Twitter at @SethGrimes 